Letter to the Editor

\title{
Single coronary artery anomaly
}

Aleksandra Gąsecka ${ }^{1}$, Olga Jakubik ${ }^{2}$, Paulina Putowska², Arkadiusz Pietrasik ${ }^{1}$

${ }^{1} 1^{\text {st }}$ Chair and Department of Cardiology, Medical University of Warsaw, Warsaw, Poland

${ }^{2}$ Medical University of Warsaw, Warsaw, Poland

Submitted: 19 March 2021

Accepted: 27 March 2021

Arch Med Sci Civil Dis 2021; 6: e50-e51

DOI: https://doi.org/10.5114/amscd.2021.105824

Copyright $\odot 2021$ Termedia \& Banach

Single coronary artery (SCA) is one of the rarest congenital coronary artery anomalies, with the incidence ranging from $0.01 \%$ to $0.07 \%$ [1]. SCA can be either an isolated anomaly or associated with other congenital abnormalities such as bicuspid aortic valve. Most of the cases of SCA are asymptomatic. The malignant variety of SCA is the type in which SCA is located between the aorta and the pulmonary artery [2].

An 83-year-old woman with suspected chronic coronary syndrome (CCS) was admitted to the cardiology department for elective coronary angiography. While performing the procedure, it was difficult to cannulate the left main artery in the left aortic sinus with JL4 and JL3.5 standard catheters. The right coronary ostium was engaged with a JR4 catheter, demonstrating a superdominant right coronary artery with additional left anterior descending and circumflex arteries arising from the right coronary ostium (Figures $1 \mathrm{~A}, \mathrm{~B}$ ). There were no significant atherosclerotic lesions in any of the branches. The patient received conservative treatment and was discharged from the hospital 1 day later.

Based on the site of origin and anatomical distribution of the branches, SCA is classified into 2 main categories: "R," right type, and "L," left type. In $75 \%$ of the cases, the artery is located between the aorta and the pulmonary artery, leading to an increased risk of sudden cardiac death due to its compression [2]. Therefore, additional assessment of the course of the vessel using computed tomography should be considered as a routine diagnostic approach [3]. Approximately $30 \%$ of the patients with malignant artery course die during the first 2 decades of life [4]. However, the clinical course in our patient was uneventful. The co-existence of SCA with CCS can have a significant impact on the course of CCS and prognosis. The anomaly may pose a diagnosis and treatment challenge during coronary catheterization and revascularisation procedures.

\section{Conflict of interest}

The authors declare no conflict of interest.

\author{
Corresponding author: \\ Aleksandra Gąsecka \\ $1^{\text {st }}$ Chair and Department \\ of Cardiology \\ Medical University \\ of Warsaw \\ Warsaw, Poland \\ Phone: +48 518343599 \\ E-mail: aleksandra.gasecka@ \\ wum.edu.pl
}



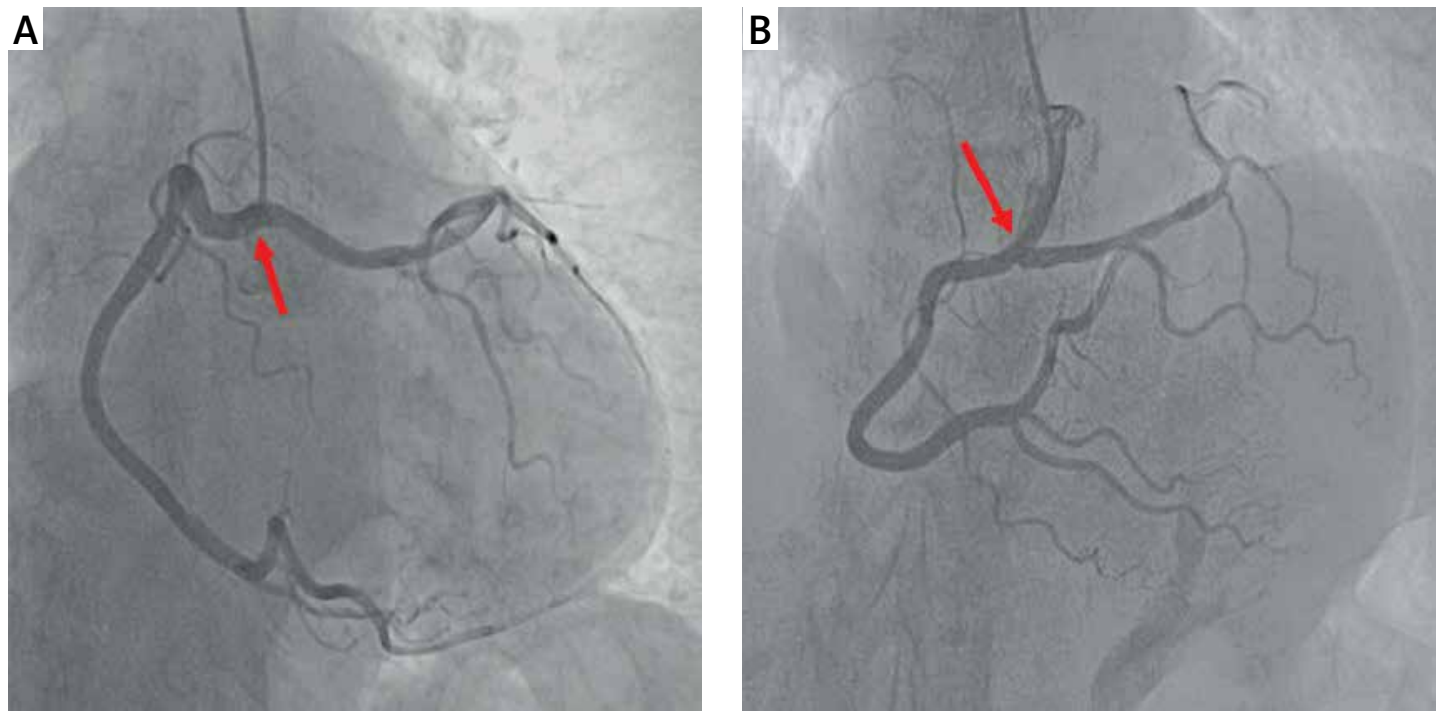

Figure 1 . Single coronary artery detected during coronary catheterization. Coronary catheterization showed a superdominant right coronary artery with additional branches arising from the right coronary ostium (red arrows). A - Left anterior oblique projection. B - Cranial anterior-posterior projection

\section{References}

1. Turkmen S, Yolcu M, Sertcelik A, et al. Single coronary artery incidence in 215,140 patients undergoing coronary angiography. Folia Morphol 2014; 73: 469-74.

2. Al Umairi R, Al-Khouri M. Prevalence, spectrum, and outcomes of single coronary artery detected on coronary computed tomography angiography (CCTA). Radiol Res Pract 2019; 2019: 2940148.

3. Kumar R, Sinha A, Shirani J. Isolated single coronary artery in adult population: a contemporary classification. J Am Coll Cardiol 2017; 69: 648.

4. Mohanty A. A review on 'single coronary artery'. Imaging Med 2015; 7: 19-20. 